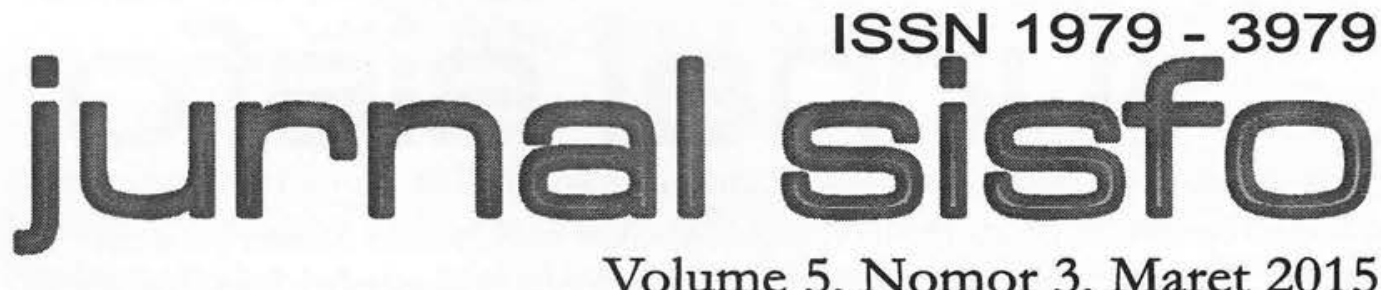

Volume 5, Nomor 3, Maret 2015

Sistem Pendukung Keputusan Pemilihan Siswa Olimpiade Sains Nasional Menggunakan Metode Profile Matching

Cut Fiarni, Tamsir Sirait, Daniel Kelah

Analisis dan Desain Website Culture-Vid Berbasis Video Share dalam Rangka Melestarikan Budaya Bangsa dan Kearifan Lokal Nusantara

Feby Atwodini Muqtadiroh, Amna Shifia Nisafani, Rifqi Rizany

Rancang Bangun Data Mart dan Purwarupa Dashboard untuk Visualisasi Performa Akademik Kurniawan Jatmika, Adhistya Erna P., Ari Cahyono

Expert E-Prescription Application (EEPA) using Forward Chaining Method Nova Eka Diana, Dwi Agung Saputra

Perencanaan Kapasitas Terminal General Cargo dengan Pendekatan Sistem Dinamik Rakhmad Maulidi, Erma Suryani

Analisis Nilai Sensitivitas untuk Mengukur Akurasi Kombinasi Kata yang Digunakan dalam Prediksi Kategori Tugas/Pekerjaan

Eko Wahyu Tyas Darmaningrat, Shu-Chiang Lin

Implementasi dan Pengujian Antarmuka Sistem Informasi Penanggulangan Kemiskinan di Kabupaten Ogan Komering Ilir

Usman Ependi

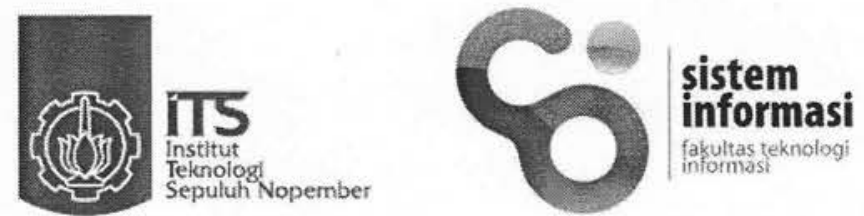

Fakultas Teknologi Informasi Institut Teknologi Sepuluh Nopember

\begin{tabular}{|c|c|c|c|c|c|}
\hline SISFO & $\begin{array}{c}\text { Volume } \\
5\end{array}$ & $\begin{array}{c}\text { Nomor } \\
3\end{array}$ & $\begin{array}{c}\text { Halaman } \\
180-403\end{array}$ & $\begin{array}{c}\text { Surabaya, } \\
\text { Mar 2015 }\end{array}$ & $\begin{array}{c}\text { ISSN } \\
1979-3979\end{array}$ \\
\hline
\end{tabular}




\section{DAFTAR ISI (LANJUTAN)}

Analisa dan Perancangan Kebutuhan Basis Data untuk Lembaga

Kursus dan Pelatihan

269-280

Hendra Dinata (Universitas Surabaya)

Rancang Bangun Data Mart dan Purwarupa Dashboard untuk Visualisasi

Performa Akademik.

Kurniawan Jatmika, Adhistya Erna P., Ari Cahyono (Universitas Gadjah Mada)

Penyusunan Perangkat Kontrol Kualitas Perangkat Lunak Berbasis ISO 25030, Studi Kasus: Aplikasi School Social Network (SSN). 292-301

Ahmad Holil Noor Ali, Adrian Nugraha Putra, Anisah Herdiyanti (Institut Teknologi Sepuluh

Nopember)

Expert E-Prescription Application (EEPA) using Forward Chaining Method... 302-307 Nova Eka Diana, Dwi Agung Saputra (Universitas Yarsi)

Perencanaan Kapasitas Terminal General Cargo dengan Pendekatan Sistem Dinamik

Rakhmad Maulidi, Erma Suryani (STIKI Malang)

Use Case Point - Activity-Based Costing: Metode Baru untuk Mengestimasi Biaya Pengembangan Perangkat Lunak.

Renny Sari Dewi, Apol Pribadi Subriadi, Sholiq (Institut Teknologi Sepuluh Nopember)

Manajemen Aset Jaringan Distribusi Energi Listrik: Sebuah Pendekatan Sistem Dinamik. 324-329

Philip F.E. Adipraja, Erma Suryani, Rully A. Hendrawan (Institut Teknologi Sepuluh Nopember)

Infrastruktur Informasi Filmless Radiology 330-342 Romeo, Febriliyan Samopa (PT. MedixSoft)

Analisis Kebutuhan Manajemen Pengetahuan pada Perusahaan Perbankan..343-351 Saide, Nesdi Evrilyan Rozanda (Institut Teknologi Sepuluh Nopember)

Rancang Bangun Data Warehouse dan Dashboard Rekonsiliasi Penerimaan Negara di Ditjen Perbendaharaan dengan Qlikview.....................................352-361
Sholiq, Rully Agus Hendrawan, Mukhamad Hafidz (Institut Teknologi Sepuluh Nopember)

Analisis Nilai Sensitivitas untuk Mengukur Akurasi Kombinasi Kata yang Digunakan dalam Prediksi Kategori Tugas/Pekerjaan. Eko Wahyu Tyas Darmaningrat, Shu-Chiang Lin (Institut Teknologi Sepuluh Nopember)

\begin{tabular}{|c|c|c|c|c|c|}
\hline SISFO & $\begin{array}{c}\text { Volume } \\
5\end{array}$ & $\begin{array}{c}\text { Nomor } \\
\mathbf{3}\end{array}$ & $\begin{array}{c}\text { Halaman } \\
180-403\end{array}$ & $\begin{array}{c}\text { Surabaya, } \\
\text { Mar 2015 }\end{array}$ & $\begin{array}{c}\text { ISSN } \\
1979-3979\end{array}$ \\
\hline
\end{tabular}




\title{
ANALISA DAN PERANCANGAN KEBUTUHAN BASIS DATA UNTUK LEMBAGA KURSUS DAN PELATIHAN
}

\author{
Hendra Dinata \\ Jurusan Teknik Informatika, Fakultas Teknik, Universitas Surabaya, \\ Jl. Raya Kalirungkut, Surabaya, 60293 \\ Telp: (031) 2981395 \\ E-mail: hdinata@staff.ubaya.ac.id
}

\begin{abstract}
Business courses and training institutions will continue to exist along with the continuous demand. These institutions can gain a competitive advantage through the application of technology based information systems. In its development, the developers of this system should be able to create a database design that is able to support the system that was developed to be implemented into a wide variety of courses and training institutes are there. To be able to generate a database design that is more general, the initial analysis is done by looking at the business processes of various types of institutions courses. From there it can be determined what data requirements contained in any business activity, then subsequently made the design of its database. The database design is made such that the design is divided into eight modules of tables design, and they are Employee tables, Event tables, Course tables, New Student Registration tables, Placement Test tables, Class Opening and Enrollment tables, Final Exam Implementation tables and Certification Exam tables. The design of the resulting database is able to accommodate all kinds of needs. Thus, this study will contribute to the developers of the system in determining the design of the database.
\end{abstract}

\begin{abstract}
Abstrak
Bisnis lembaga kursus dan pelatihan akan terus ada seiring dengan adanya permintaan yang terus menerus. Lembaga-lembaga ini dapat memperoleh keuntungan kompetitif melalui penerapan teknologi berbasis sistem informasi. Di dalam pengembangannya, para pengembang sistem ini harus dapat membuat sebuah rancangan basis data yang mampu mendukung sistem yang dikembangkan agar dapat diimplementasikan ke berbagai macam variasi lembaga kursus dan pelatihan yang ada. Untuk dapat menghasilkan suatu rancangan basis data yang lebih bersifat general, analisa awal dilakukan dengan melihat proses bisnis dari bermacam jenis lembaga kursus. Dari situ dapat diketahui kebutuhan data apa saja yang terdapat di dalam setiap aktivitas bisnis, kemudian selanjutnya dibuatkan rancangan basis datanya. Rancangan basis data dibuat sedemikian rupa yang terbagi menjadi delapan modul rancangan tabel-tabel yaitu rarcangan tabel Karyawan, tabel Event, tabel Kursus, tabel Pendaftaran Siswa Baru, tabel Tes Penempatan, tabel Pembukaan dan Pendaftaran Kelas, tabel Pelaksanaan Ujian Akhir, dan tabel Ujian Sertifikasi. Rancangan basis data yang dihasilkan tersebut mampu mengakomodir setiap macam kebutuhan. Dengan demikian penelitian ini dapat memberikan kontribusi bagi para pengembang sistem dalam menentukan rancangan basis datanya.
\end{abstract}

Kata kunci: basis data, rancangan, lembaga kursus

\section{PENDAHULUAN}

Dalam rangka untuk menumbuhkembangkan potensi diri, manusia membutuhkan pendidikan. Selain mengikuti proses pendidikan yang diselenggarakan di sekolah-sekolah, pendidikan itu masih bisa diikuti di luar sekolah dalam bentuk kursus atau pelatihan. Siswa sekolah di kebanyakan negara berkembang, banyak yang mengikuti pendidikan tambahan di luar sekolahnya berupa progam bimbingan belajar. Seperti yang dikemukakan oleh Jayachandran (2014), adanya tuntutan akan kelulusan pada ujian akhir nasional, menumbuhkan permintaan yang besar dari para siswa sekolah akan program bimbingan belajar tambahan. Sementara Ünal et. al. (2010) mengatakan bahwa program bimbingan belajar dibutuhkan para siswa demi mencapai cita-citanya untuk dapat melanjutkan pendidikannya ke jenjang yang lebih tinggi. Di samping bentuk bimbingan belajar, Yew (2011) juga mengatakan bahwa program pelatihan kerja juga dibutuhkan demi peningkatan karir kerja seseorang. Sebab melalui program pelatihan, menurut Tsai dan Tai (2003) manusia dapat meningkatkan pengetahuan dan ketrampilannya demi tercapainya daya saing di dunia kerja. Secara mendasar, Ditjen Paudni (2014) menggarisbawahi bahwa berbagai bentuk kursus 